Contemporary Research in Education and English Language Teaching

ISSN: 2641-0230

Vol. 3, No. 1, pp. 1-8

2021

Publisher: Learning Gate

DOI: 10.33094/26410230.2021.31.1.8

(C) 2021 by the authors; licensee Learning Gate

\title{
Implications of Counselling, Psychological and Social Services on Academic Performance of Primary School Pupils in Southwest, Nigeria
}

\author{
Alebiosu, Eunice Oluwayemisi \\ Department of Human Kinetics and Health Education, Faculty of Education, Ekiti State University, Ado-Ekiti, Ekiti State, Nigeria. \\ Email: oluyemisialebiosu@gmail.com \\ Akintoke, Victor Akin \\ Department of Guidance and Counselling, Faculty of Education, Adekunle Ajasin University, Akungba-Akoko Ondo State, Nigeria. \\ Email:akintoke.victor@yahoo.com \\ Oginni, Omoniyi Israel* \\ Department of Science Education, Faculty of Education, Ekiti State University, Ado-Ekiti, Ekiti State, Nigeria. \\ Email: omoniyi.oginni@eksu.edu.ng (*Corresponding Author)
}

Received: 15 June 2021; Revised: 6 July 2021; Accepted: 28 July 2021; Published: 23 August 2021

Abstract: The study examined implications of counselling; psychological and social services on academic performance of primary school pupils in Southwest, Nigeria. The study adopted a descriptive survey research design. The population consisted of all primary school teachers in Southwest out of which 1006 teachers were selected from the three sampled states in Southwest, Nigeria. Multistage sampling procedure was used to select sample for the study. The instrument used for data collection was tagged Implications of Counselling, Psychological and Social Services Questionnaire "(CPSSQ)" and a proforma titled "Data Retrieval Format" (DRF). CPSSQ comprised of two sections. Section A sought information on the bio data of the respondents while Section $B$ was used to elicit information on implications of psychological, emotional and social dimensions of the pupils' health. The instrument was validated by experts in Guidance and Counselling, Human Kinetics and Health Education and Tests and Measurement. The reliability of the instrument was ensured by using Pearson's Product Moment Correlation analysis and had reliability co-efficient of 0.86 , which was adjudge high enough and considered the instrument to be reliable. One general question was raised and one null hypothesis was formulated for the study. The study revealed that counselling, psychological and social services had implications on school health programme. It was therefore recommended that the status of school health programme in Southwest should be improved upon, considering its importance to the survival and academic performance of the school pupils.

Keywords: School Health, Counselling, Psychological, Social services, Academic performance.

\section{Introduction}

Health is an important factor in national development, and it has become one of a test of civilization for any nation. The quality of a man's health is determined by the quality of health care services he or she receives. By implication, the strength of a nation could be linked to the wellness and healthy condition of her citizenry. Oginni (2013) affirmed that individual characteristics such as health and physical statures should not be downplayed due to its contributory factor to students' educational efforts in schools. Infact, for a nation to be tagged a wealthy nation, such a nation suppose to have a strong health system that can stand the test of time. The United Nations now seems to be using health status of a nation as a barometer for measuring the wealth of any nation. 
According to Federal Republic of Nigeria (2013) the United Nations International Children Emergency Fund (UNICEF) and United Nations (UN) General Assembly unanimously adopted the rights of the children as encapsulated among these rights is the child's entitlement to social security which includes good nutrition, housing, medical care, free and compulsory education. In the same vein, African Union (AU) Charter stated that every child is entitled to compulsory basic education depending on individual's ability. Nigeria as a member of both associations in 1990 endorsed the right of the child. Also, the Federal Republic of Nigeria (2013) supported the promotion of the emotional, physical and psychological health of all children through school health education programme.

Therefore, health, psychology and social services in education go paripassu and seek to achieve development of the appropriate school health programme for school pupils. Nigeria with approximately over 180 million people out of which over $44 \%$ are under 15 years of age with health indicators of high morbidity and mortality rate by UNESCO (2019) discovered that schools are ideal places to reach out to children and youth, because children's health and learning are linked. Children cannot learn when they are sick or when health concerns interrupt their ability to concentrate. This makes school health programme all over Nigeria aims at health promotion, protection, maintenance and conservation. All these are associated with health instructions based together to ensure physical, mental and social wellbeing of pupils and school staff. According to Alebiosu and Ibijola (2017), health has been widely misconceived to mean nothing more than a situation in which an individual is neither sick nor injured. Meanwhile, health is a state of "complete physical, mental and social well-being and not merely the absence of diseases or infirmity" which means mere absence of diseases alone does not guarantee good health. For school pupils, school health programme can have more immediate consequences and better performance in school. However, documentation on health and wellness of children in the teaching of sciences and Mathematics in school setting was unacceptably low. Oginni (2013)

School health programme is the totality of procedures designed to protect and promote the wellbeing of students and staff in schools (Alebiosu \& Ibijola, 2017). Lucas and Gilles (2006) posited that children at school are exposed to variety of hazards such as physical injuries, infection and emotional problems that are detrimental to their optimal growth and development and hence, the need to make their health need a priority above other things. Lucas and Gilles further asserted that, for our children to attain greater height in education, their academics and health must be laid on solid foundations in order to develop strong potentials in achieving their goals in life. Therefore, a healthy school environment, adequate nutrition, affective school health services and psycho-social counselling are all required to provide the child with the best opportunity of making the appropriate adjustments that are required during critical period. Although, there are key areas in which schools can take action to improve the health and performance of students (Oginni, 2013). Such areas include hygienic check, feeding programme initiatives, regular health talk among others

The school health programme is designed to enable children and youths to enhance their health and to develop their fullest potentials by achieving good health as well as by acquiring education. Abidoye and Akintoye (2001) stated that school health programme reinforces community health and improves educational programme. It appears that school health programme strives to provide healthful school living for the school population, protect children from diseases, discover physical, social and emotional defects and other abnormal conditions like, heart defects, cleft lip/palate, down syndrome and spinal bifida in the school child and to promote their corrections where remediable through effective counselling of parents, care-givers and the children. The tasks of school health programme are manifold and it could not only be handled by school health educators but other stake holders such as nongovernmental agencies, guidance counsellors, Parent-Teachers Association, care givers and the community at large for huge successes to be recorded in the practice especially in the Southwest, Nigeria. Akintoke (2019) posited that children and schools have a huge role in bringing out the best in children. Good conduct is coveted, but sometimes, young minds need guidance to polish their personality, health and hygiene. Akintoke reiterated that through counseling, children are given advice on how to manage and deal with emotional conflicts and personal problems. Counselling will help to 
incorporate valuable lessons in the children's daily life and properly guided them on how to deal with psychological problems which can badly impact their studies and health.

Similarly, Udoh (2001) emphasized that school health programme is a procedure and activities are designed to protect and promote the well-being of students and the school staff as this activity contributes to understanding, maintenance and improvement of the health of the school population. Ross (2002), Udoh (2001) posited that the objective of school health programme synthesized from several sources indicate that it seeks to provide healthful school living for the school population, develop knowledge and attitudes that will enable the individual to make intelligent health decisions and to promote desirable health habits, provide for the establishment of a sound social and emotional climate and sanitary physical plant that will protect children from communicable and other diseases such as influenza ,corona virus, pertussis, pink eye and shigellosis and to promote their correction where remediable, develop each child to his optimum health level through the efforts of home, school and community involvement and participation. It will also provide for constant and continued appraisal of the school-age children's health status, provide for prompt emergency care due to sudden illness or injury and to develop school, home and community cooperation in health protection, promotion and maintenance of the children. Nevertheless, counselling, psychological and social services are the activities that focus on cognitive, emotional, behavioural and social needs of school pupils, individuals, groups and families (Lucas \& Gilles, 2006). This is designed to prevent and address problems, facilitates positive learning and healthy behaviour and enhances healthy development in school pupils. Alebiosu and Olanipekun (2015) opined that counselling includes organizational assessment and consultation skills of counsellors and psychologists as this does not only contribute to the health of students but also to the health of the school environment and the hosts communities in general. Counselling is a procedure whereby children and parents are informed of the children's health needs and problems so that necessary actions are taken to solve these problems and necessary corrections are made where remediable. He emphasized that health educators, counsellors, psychologists and other social services providers in the school should focus on the objectives of interpreting the significance of health conditions to parents and to encourage them to obtain needed treatments for their wards. Health educators and counsellors provide to students and parents better understanding of their health needs and the procedures that should be followed in order to satisfy them. They also serve as device for health education as the parents and children are motivated to alter their behaviour in accordance with acceptable health counselling standards. Health counselling can help to develop a feeling of responsibility in pupils and parents for correction of health defects and for promoting school and community health programme. Emenike (2001) discovered that many children and learners are from broken homes, low-social economic backgrounds and other psych-social problems that infringe on their readiness to learn effectively. Health counselling can be provided by the school counsellors, health teachers, medical doctors, nurses, psychologists and other health educators to help students to take responsible decisions on all matter relating to their health and behaviour. Counselors and psychologists in the school can provide pupils and parents with a better knowledge of their health challenges and psychological needs and the steps that should be taken to solve these challenges, meet the needs and serve as a means for rolling back ignorance and push forward knowledge on the part of parents and other care givers.

\subsection{Statement of the Problem}

Over the years, public primary schools in South west, Nigeria seem to be suffering from total neglect in terms of personnel such as guidance counsellor, health educators and psychologist due to non-recruitment of these essential staff as a result of government policies. This inadvertently affects the education, health, the general growth and development of these children. This might have been the reason why an average parent in the Southwest, Nigeria prefers to enroll their children and wards in private schools where it seems these categories of personnel are available despite the costlier school fees and less staffed with qualified subject teachers. 
The researchers also observed that since the health conditions of school pupils are neglected to the extent that many of them suffer from one illness or the other ranging from minor to major illness, leading to stunted growth and maladjusted behaviours, in some of the pupils attending clinics and hospitals during the school hours. It was also observed that school children suffer from preventable diseases like malnutrition, anemia, hearing impairment, partial or total blindness due to the absence of these essential staff that are vital to the social and health needs of school pupils as they are not recruited by the governments at all levels. If these diseases are detected early and counsellors, psychologists and health workers are adequately informed, such would have been treated and permanent damages avoided. The morbidity and mortality rate of school aged children seems to be very high in Southwest, Nigeria and that children still suffer from communicable diseases like measles, chicken pox, polio mellitus, hepatitis, tetanus and malnutrition due to lack of effective school health programme.

\subsection{Purpose of the Study}

The purpose of this study was to examine implications of counselling, psychological and social services, on academic performances of school pupils in public primary schools in Southwest, Nigeria. It also examined the roles of guidance counsellors in school health programme.

\subsection{Research Questions}

The following research question was raised for the study;

(i) Is there any implications of counselling, psychological and social services on academic performance of pupils in South west, Nigeria?

\subsection{Hypothesis}

A null hypothesis generated for this study was;

(ii) There is no significant relationship between counselling, psychological, social services and academic performance of school pupils in Southwest, Nigeria.

\subsection{Significance of the Study}

The outcome of this study would be of value to students, parents, teachers, government and school pupils in preventing several health problems in the schools. The findings of this study would assist to promote pupils' health and develop pupils potentials by adopting good health habits as well as acquiring education.

Findings from the study would also reinforce community health and health education programmes. Counsellors, health educators and other education stake holders would find the study as a useful guide to develop in clients and other learners basic traits for the purpose of improving health and learning abilities. Parents and care givers will also find the study significant as their involvement in school health programme could promote community involvement and participation thereby strengthening community ownership in schools. The findings would also help curriculum planners, educational authorities and other stakeholders to plan and implement policies that will encourage effective counselling, psychological and social services that would help to discover and prevent devastating health problems in school pupils.

\section{Methodology}

The descriptive survey design was used for the study. The design used was considered appropriate because it focuses on the observations of a large number of people and their perception of the existing situation. The population for the study consisted of all the health education teachers or health educators in all primary schools in Southwest, Nigeria. Southwest Nigeria consisted of 6 States namely Ekiti, Lagos, Ogun, Ondo, Osun and Oyo States. 
There were 144,862 teachers and 2,602,133 pupils in all the primary schools in Southwest, Nigeria, culled from Nigeria Digest of Education /Statistics (2013-2019). The sample for this study consisted one thousand and six $(1,006)$ teachers from the various primary schools sampled in Southwest, Nigeria. The sample was selected using multistage sampling procedure and purposive sampling technique. In the first stage, three (3) states were selected within the Southwest through the use of simple random sampling techniques. The states were Ekiti, Ondo and Osun. The second stage was the selection of Local Government Areas randomly from each of the states sampled. Five (5) Local Government Areas were selected in Ekiti, four (4) Local Government Areas were selected from Ondo State, while three (3) Local Government Areas were selected in Osun State using random sampling technique. The third stage was the selection of primary schools in each of the Local Government Areas sampled using simple random sampling techniques. 55 primary schools were selected in Ekiti, 45 were selected from Ondo as 20 primary schools were selected in Osun States. The fourth stage involved the selection of respondents, 8 respondents were purposively selected from each of the 55 primary schools sampled in Ekiti, 8 respondents were selected in each of the 45 primary schools sampled in Ondo, while 10 respondents were selected from each of the 20 primary schools sampled in Osun states including six (6) head teachers. The respondents were either health education teachers or health educator from each of the schools sampled.

A self -structured questionnaire titled " Implications of Counselling, Psycological and Social Services Questionnaire (CSSQ)" was used to collect relevant data for this study. The second instrument was a proforma titled "Data Retrieval Format" (DFR) which was used to collect the result of placement examination of primary six pupils to JSS 1, from 2015-2017. The instrument was divided into sections A \& B: Section A contained information on bio data of the respondents. Section B was used to elicit information that addresses the psychological physical, mental, emotional and social dimensions of the pupils health. The information was collected using Likert-rating scale viz: Strongly Agree $(\mathrm{SA})=4$, Agree $(\mathrm{A})=3$, Strongly Disagree $(\mathrm{SD})=2$ and Disagree $(\mathrm{D})=1$. The data collected were analysed using Pearson Product Moment Correlation analysis at 0.05 level of significance.

\subsection{Validity of the Instrument}

To determine the extent to which the instruments used in this study measure what they were supposed to measure, three methods of validity were adopted viz: face, content and construct validity. The face validity was ensured by allowing other experts to assess the content of the items, while content validity aims at establishing whether the content being measured represents the content or substance of the property to be measured.

The face and content validity was determined by subjecting the instruments "CSSQ" and the "DRF" to thorough screening by experts in Guidance and Counselling, Human kinetics and Health Education and Tests and Measurement in the Faculty of Education, Ekiti State University, Ado-Ekiti. For the construct validity, convergent method was used to ascertain the construct validity of the questionnaire by comparing the new instruments with another standardized instrument titled "Linkages between Student Health and Academic Achievements (LBSHAA). The results were correlated using Pearson's Product Moment Correlation Analysis at 0.05 Significant Level. A co-efficient of 0.86 was obtained which represented relatively high degree of validity. The instruments were administered by the researchers with the assistance of two trained research assistants.

\subsection{Reliability of the Instrument}

A test-re-test method was used to determine the reliability of the instrument by administering the test twice to thirty teachers who are not part of the actual sample for the study respectively with a time interval of two-weeks. The results obtained were subjected to Pearson's Product Moment Correlation Analysis with a co-efficient of 0.86 obtained which was considered high and reliable enough to establish the reliability of the instrument. 
Table-1.

Frequency counts on Counselling, Psychological and Social Services of School pupils.

\begin{tabular}{|c|c|c|c|c|c|c|c|c|c|}
\hline $\mathbf{S} / \mathbf{N}$ & COMMENT & $\mathbf{S A}$ & $\% \mathrm{SA}$ & A & $\% A$ & D & $\% \mathrm{D}$ & SD & \%SD \\
\hline 1. & $\begin{array}{l}\text { There is an effective and } \\
\text { consistent health instruction } \\
\text { system in the school. }\end{array}$ & 280 & 27.8 & 547 & 54.4 & 123 & 12.2 & 56 & 56 \\
\hline 2. & $\begin{array}{l}\text { Health education/Health } \\
\text { Science is taught and offered as } \\
\text { a subject in the school }\end{array}$ & 427 & 42.4 & 501 & 49.8 & 49 & 4.9 & 29 & 2.9 \\
\hline 3. & $\begin{array}{l}\text { The pupils are always instructed } \\
\text { on the theory and practice of } \\
\text { safety }\end{array}$ & 316 & 31.4 & 596 & 59.2 & 59 & 5.9 & 35 & 3.5 \\
\hline 4. & $\begin{array}{l}\text { Varieties of instructional } \\
\text { materials such as radio, audio- } \\
\text { visual and graphics are } \\
\text { employed for the health } \\
\text { instruction purpose }\end{array}$ & 128 & 12.7 & 277 & 27.5 & 387 & 38.5 & 214 & 21.3 \\
\hline 5. & $\begin{array}{l}\text { Health personnel are sometimes } \\
\text { brought to the school to educate } \\
\text { the pupils and staff }\end{array}$ & 281 & 27.9 & 483 & $\begin{array}{c}48.9 \\
0\end{array}$ & 160 & 15.9 & 82 & 8.2 \\
\hline 6. & $\begin{array}{l}\text { Pupils are always instructed on } \\
\text { personal and environmental } \\
\text { hygiene }\end{array}$ & 396 & 39.4 & 499 & 49.6 & 59 & 5.9 & 52 & 5.2 \\
\hline 7. & $\begin{array}{l}\text { Field trips are usually arranged } \\
\text { for the pupils to visit places of } \\
\text { health significance. }\end{array}$ & 121 & 12.0 & 330 & 32.8 & 351 & 34.9 & 204 & 20.3 \\
\hline 8. & $\begin{array}{l}\text { The school library has adequate } \\
\text { and current health textbooks, } \\
\text { for pupils and staff use. }\end{array}$ & 155 & 15.4 & 446 & 44.3 & 242 & 24.1 & 163 & 16.2 \\
\hline 9. & $\begin{array}{l}\text { Practical sections are integrated } \\
\text { into the instruction network of } \\
\text { the pupils. }\end{array}$ & 132 & 13.1 & 447 & 47.4 & 267 & 26.5 & 130 & 12.9 \\
\hline 10. & $\begin{array}{l}\text { School health instructions are } \\
\text { sometimes extended to parents } \\
\text { and guardians. }\end{array}$ & 179 & 17.8 & 563 & 56.0 & 166 & 16.5 & 98 & 9.7 \\
\hline 11. & $\begin{array}{l}\text { Health education is offered in all } \\
\text { teachers' preparatory colleges. }\end{array}$ & 257 & 25.5 & 580 & 57.7 & 106 & 10.5 & 63 & 6.3 \\
\hline 12. & $\begin{array}{l}\text { Health educators are well } \\
\text { prepared to teach health } \\
\text { instruction in schools. }\end{array}$ & 280 & 27.8 & 466 & 46.3 & 180 & 17.9 & 80 & 8.0 \\
\hline 13. & $\begin{array}{l}\text { Health educators are able to } \\
\text { identify some health problems } \\
\text { through careful observation of } \\
\text { the pupils }\end{array}$ & 273 & 27.1 & 522 & 51.9 & 129 & 12.8 & 82 & 8.2 \\
\hline 14 . & $\begin{array}{l}\text { School health education is } \\
\text { crucial and fundamentally basic } \\
\text { for maintenance of the health of } \\
\text { school pupils. }\end{array}$ & 286 & 28.4 & 568 & 56.5 & 92 & 9.1 & 60 & 6.0 \\
\hline \multirow[t]{3}{*}{15.} & $\begin{array}{l}\text { Health habits learned in school } \\
\text { by pupils may persist } \\
\text { throughout life. }\end{array}$ & 355 & 35.3 & 511 & 50.8 & 79 & 7.9 & 51 & 5.1 \\
\hline & Total & $\begin{array}{c}386 \\
6\end{array}$ & 384 & 7366 & 732 & 2449 & 243.5 & 1399 & 139.4 \\
\hline & Mean & 258 & 25.6 & 491 & 48.8 & 163 & 16.2 & 93 & 9.3 \\
\hline
\end{tabular}




\section{Results}

The research question is there any relationship between counselling, psychological and social services and academic performance of school pupils? The instrument was subjected to frequency counts, percentages, means and standard deviation.

Table 1 showed that counselling, Psychological and Social Services had a means score of $79.8 \%$ to fall to the category of moderate level.

\section{Research Hypothesis.}

A null hypothesis was postulated and tested at 0.05 level of significance

1. There is no significant relationship between counselling, psychological and social services and academic performance of school pupils.

Table-2.

Pearson's Product Moment Correlation Analysis of Relationship between Counselling, Psychological and Social Services and Academic Performance of School Pupils

\begin{tabular}{l|c|c|c|c|c}
\hline Variables & $\mathbf{N}$ & Mean & SD & r-cal & r-tab \\
\hline Counselling, Psychological and Social Service & 1006 & 3.02 & 0.52 & 0.217 & 0.195 \\
\hline Academic Performance & 1006 & 1.86 & 0.03 & & \\
\hline Note: $P<0.05$ significant level
\end{tabular}

Table 2 above revealed a positive relationship between Counselling, Psychological and Social services and academic performance of school pupils in Southwest, Nigeria. The result obtained showed that $\mathrm{r}$-cal $=(0.217)$ was greater than $r$-tab $=(0.195)$ at 0.05 level of significant. Therefore, the null hypothesis is rejected, which implies that there is a significant relationship between counselling, psychological and social services and academic performance of primary school pupils. This finding was in line with Emenike (2001) that health counselling would provide pupils and parents with a better understanding of their health needs and the procedures that should be followed in order to satisfy these needs. It will also serve as a device for health education in order to develop sound health defect. Lucas and Gilles (2006) supported the findings and reported that social services was seen as the activities that focus on cognitive, emotional, behavioural and social needs of school pupils and their families. He further stressed that it was designed to prevent and address problems, facilitate positive learning and healthy behaviour and enhance healthy and mental development in school pupils. Similarly, the finding was also supported by Akintoke (2019) who posited that children and schools have a huge role in bringing out the best in children. Good conduct is coveted, but sometimes young minds need guidance to polish their personality, health and hygiene. He further revealed that through counselling, children are given advice on how to manage and deal with emotional conflicts and personal problems as counseling will help incorporate valuable lesson in their daily life and properly guided on how to deal with psychological problems which can badly impact their studies and health.

\section{Conclusion}

The study investigated the implications of counselling, psychological and social services on academic performance of pupils in Southwest, Nigeria. It was concluded that level of response on counselling, psychological and social services of school pupils was at moderate. The only hypothesis generated for the study was rejected which implies that there was a significant implication of counselling, psychological, social services on academic performance of pupils in Southwest, Nigeria.

\section{Counselling Implications and Recommendations}

The ultimate aim of counselling is behavioural change. Counsellors are trained to modify behaviuors of all categories of individuals because it is a helping relationship which is concerned with helping the school pupils, students, clients and parents who are confused or experiencing maladaptive 
behaviours to have positive change through an exercise, self-understanding and environmental awareness. Counselling serves as one of the educational methods most frequently used in health education to help individuals and families. During counselling, a person with a need (the client) and a person who provides support and encouragement (the counsellor) meet and discuss in such a way that the client gains confidence in his or her ability to find solutions to their problems. Counsellors stand to encourage individuals or groups to do what they cannot do themselves in order to be able to support their members in the practice of improving their health behaviours. Counselling is a helping process where one explicitly and purposefully gives his or her time to assist people to explore their own situation, and act on a solution. Counselling could assist an individual to identify his or her problems so that they will be able to discover the causes of their problems and offer appropriate solution through effective counselling.

Therefore, guidance counsellors should intensify efforts in guiding parents and pupils on the menace of health challenges on academic performance of the school pupils and to the society at large. Counsellors should work hand in hand with other education stakeholders to encourage the pupils to practice personal hygiene and safety practices like the use of face mask, regular hand washing and maintenance of social distancing in schools.

Government, health educators, guidance counsellors and other stakeholders should design educative programmes that would address current health issues to benefit young school pupils and staff. Inservice training and exposure to seminars and workshop that are relevant to teaching should be given to teachers and other health personnel in the schools.

Government and school administrators should ensure adequate provisions of portable water and toilet facilities for all primary schools in Southwest, Nigeria for the use of pupils and staff. This will encourage a safe and healthy school environment that is free from transferring of communicable diseases. Qualified personnel should be recruited like guidance counsellors, psychologists and health educators to assist in raising the standard of pupils health in the schools.

\section{References}

Abidoye, O., \& Akintoye, T. (2001). Effect of nutrition on academic performance of school pupils. Journal of Status of Intellectual Performance of Nigerian Children Early Child Development and Care, 6(1), 87594.

Akintoke, V. A. (2019). Influence of duration of marriage couples on domestic violence in Ekiti State. Journal of Measurment and Evaluation, Department of Guidance and Counselling, Faculty of Education, Adekunle Ajasin University, Akungba- Akoko, Ondo State, 2(1), 56-66.

Alebiosu, E. O., \& Ibijola, E. Y. (2017). Assessing strategies of school health programme as a tool for improving the health status of primary school children in Nigeria. International Research Journal, 7(7), 167-172.

Alebiosu, E. O., \& Olanipekun, J. A. (2015). Enhancing pupils academic performancethrough effective school health services. Journals of Curriculum Studies, $10(11), 116-122$.

Emenike, E. U. I. (2001). A case for sex education in Nigeria, post-primary schools. Nigeria School Health Journal, 6(3), 24 -31.

Federal Republic of Nigeria. (2013). National policy on education (Vol. 3). Jibowu Street Yaba, Lagos-Nigeria: NERDC Press.

Lucas, A. O., \& Gilles, H. M. (2006). Text book of public health medicine for the tropics. London: Printed by Holder Education.

Oginni, O. I. (2013). The relationships between secondary school students' body parameters and their mathematics performance in southwest Nigeria empirical education research (pp. 101-111). U.S.A: Letting the Data Speak for Themselves Untested Ideas.

Ross, C. E. (2002). Education, age and the cumulative advantage in health. Journal of Health and Social Behavior, 37(1), 104-120. Udoh, C. O. (2001). Teaching health education. Lagos: Kitams Publishers Ltd.

UNESCO. (2019). Combining data on out-of- school children, completion and learning to offer a more comprehensive view on SDG 4, UNESCO Institute of Statistics, Canada. Paper No 61. 